\title{
Genus Stereodytis Meyrick (Lepidoptera: Oecophoridae) of China, with descriptions of two new species
}

\author{
Shuxia Wang \& Roger C. Kendrick
}

Wang, S. \& Kendrick, R. C. 2009: Genus Stereodytis Meyrick (Lepidoptera: Oecophoridae) of China, with descriptions of two new species. - Entomol. Fennica 20: 186-190.

Two new species of the genus Stereodytis Meyrick, S. brevignatha sp. n. and $S$. acutidens sp. n. are described from China, and Stereodytis increta (Meyrick), comb. n. is transferred from Eulechria Meyrick. The generic characters are emended with description of both male and female genitalia given for the first time. Photographs of the adults and the genitalia are provided.

S. Wang, College of Life Sciences, Nankai University, Tianjin 300071, China; Corresponding author's e-mail: shxwang@nankai.edu.cn.

R. C. Kendrick, Fauna Conservation Department, Kadoorie Farm \& Botanic Garden,TaiPo,New Territories, Hong Kong,China; E-mail: moths@kfbg.org.

Received 2 September 2008, accepted 30 September 2008

\section{Introduction}

The genus Stereodytis has been known as a monotypy since it was erected by Meyrick (1914) based on specimens collected in Sri Lanka. It is characterized by the dark coloured body, the more or less beaklike gnathos with teeth along dorsal margin basally and the large thornlike cornutus in the male genitalia. In this paper, we present three species from China based on specimens collected from Gansu, Guizhou, Anhui, Hunan and Hong Kong, including two new species and a new combination. A discussion is provided for the taxonomic placement of $S$. increta (Meyrick).

\section{Material and methods}

Adult specimens were collected by light traps in different nature reserves or mountainous areas in Gansu, Guizhou, Hunan and Hong Kong, China. External characters of adults were examined us- ing an Olympus SZX9 stereo-microscope (maximum magnification 228X). Color is based on the observations of the whole specimen illuminated with cold and white light. Wing venation and genitalia were examined using specimens mounted in Canada balsam basically following the techniques of Li and Zheng (1996). All the studied specimens are deposited in the Insect Collection, College of Life Sciences, Nankai University, Tianjin, China.

\section{Descriptions}

\subsection{Genus Stereodytis Meyrick, 1914}

Stereodytis Meyrick, 1914: 238.

Type species: Stereodytis crithina Meyrick, by monotypy.

Description. Adult. Head with roughened piliform scales on vertex; ocellus present. Antenna about $2 / 3$ length of forewing, ciliate, stout in male; scape with pecten along anterior margin on 
basal half. Labial palpus recurved; second segment thickened with appressed scales; third segment as long as or slightly shorter than second, acute apically. Maxillary palpus short, filiform. Forewing lanceolate, apex rounded; $\mathrm{R}_{1}$ from middle, $\mathrm{R}_{4}$ and $\mathrm{R}_{5}$ stalked, $\mathrm{R}_{5}$ reaching apex, $\mathrm{CuA}_{1}$ from angle, $1 \mathrm{~A}$ and $2 \mathrm{~A}$ furcate. Hindwing elongate ovate, $\mathrm{M}_{3}$ and $\mathrm{CuA}_{1}$ stalked, Rs and $\mathrm{M}_{1}$ parallel.

Male genitalia: Uncus somewhat triangular. Gnathos strong, beaklike, basally with dense teeth along dorsal portion. Tegumen broad. Valva with long and thin process from middle near base extending downward to base of juxta; cucullus tapering to narrowly pointed apex; transtilla weak, band-formed, slightly arched upward; sacculus broad, sclerotized. Vinculum narrow, bandlike. Saccus short. Juxta developed. Aedeagus strong, slightly curved near base; cornutus being a large thorn.

Female genitalia: Apophyses posteriores slender and straight; apophyses anteriores shorter than apophyses posteriores, curved near middle. Ductus bursae membranous except partially sclerotized near base. Corpus bursae membranous; signum present.

Biology. Little is known about the biology. The collection information by light traps indicated that adults of the genus emerged from February through October.

Distribution. Stereodytis is known in Sri Lanka and China.

\subsection{Stereodytis increta (Meyrick, 1931), comb. n. (Figs. 1a-b, 2a)}

Eulechria increta Meyrick, 1931: 187.

Materials examined. China: 4 $\widehat{\jmath}$, Zhangjiajie $\left(29.49^{\circ} \mathrm{N}, 110.26^{\circ} \mathrm{E}\right)$, Hunan Province, alt. $650 \mathrm{~m}$, 7.-11.VIII.2001, leg. Houhun Li and Xinpu Wang; $1 \partial^{\lambda}$, Mt. Fanjing $\left(27.55^{\circ} \mathrm{N}\right.$, $\left.108.41^{\circ} \mathrm{E}\right)$, Guizhou Province, alt. 1,300 m, 4.VII.2001, leg. Houhun Li and Xinpu Wang; 2

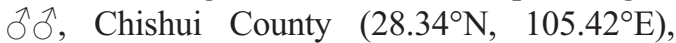
Guizhou Province, alt. 390 m, 27, 30.V.2000, leg. Yanli Du; $1{ }^{\curvearrowright}$, Wen County $\left(32.58^{\circ} \mathrm{N}, 104.41^{\circ} \mathrm{E}\right)$, Gansu Province, alt. 860 m, 11.VII. 2005, leg. Haili Yu.

Description. Adult (Figs. 1a-b): Wing ex- panse 16.0-20.0 mm. Head pale greyish yellow, with appressed scales on vertex and frons. Antenna with scape pale greyish yellow; flagellum dark brown. Labial palpus pale greyish yellow, covered with dense dark brown scales on outer surface, or dark brown except for greyish yellow at apices of second and third segments; second segment slightly reaching beyond vertex; third segment slightly shorter than second, pointed. Thorax and tegula deep greyish brown except greyish white posteriorly. Forewing with costal margin gently arched, termen obliquely rounded; ground color light grey, suffused with dark brown; dark brown scales becoming denser at base, along costal margin and at apex, somewhat forming inconspicuous spots; discal, plical and discocellular stigmata black, small and rounded; tornal stigma indistinct; fringe greyish brown except basal $1 / 3$ pale greyish yellow. Hindwing pale greyish brown; fringe grey except greyish yellow at base. Fore leg black; mid leg greyish black, greyish ochreous at apices of tibial and tarsal segments; hind leg pale greyish ochreous, with scattered brown scales.

Male genitalia (Fig. 2a): Uncus triangular, broad at base, narrowed to apex; apex with a small incision at middle, laterally forming pair of small processes. Gnathos wide at base, narrowed to pointed apex, gently curved downward at distal $1 / 3$; dorsal $2 / 5$ with dense teeth. Valva broad basally, gradually narrowed to about $4 / 5$; cucullus being a broad thumblike process, finely setose, curved ventrally, rounded apically; transtilla slightly arched upward. Sacculus broad and sclerotized, about same width, slightly curved beyond middle. Saccus triangular, rounded anteriorly. Juxta elongate olivary. Aedeagus slightly shorter than valva; cornutus conical, roundly dilated at base, pointed at apex, slightly longer than $1 / 3$ of entire length of aedeagus.

Distribution. China (Gansu, Guizhou, Hunan, Sichuan).

Remarks. This species was described by Meyrick based on a male specimen collected in Mt. Emei, Sichuan Province, China. It was originally placed in the genus Eulechria Meyrick, 1883, which is an Australasian endemic taxon. Common (1997) regarded the five Meyrick species distributed outside Australia and figured by Clarke (1963) as incorrectly assigned to Eu- 


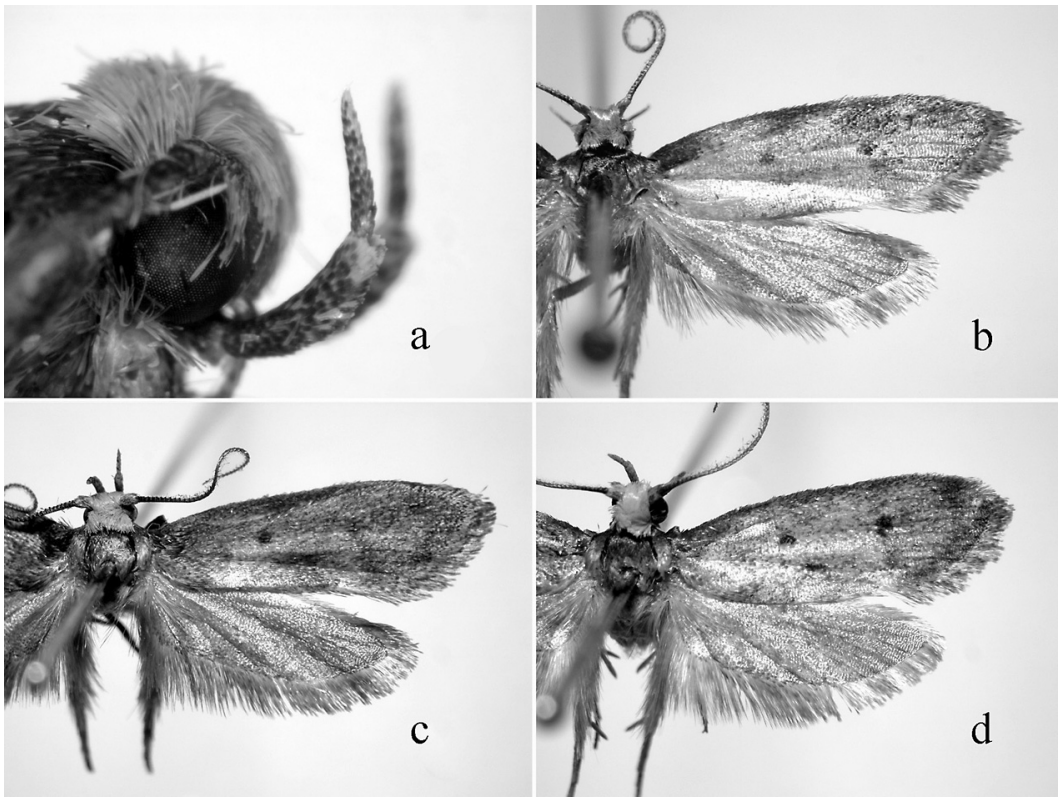

Fig. 1. Adults of Stereodytis spp. - a-b. S. increta (Meyrick) ( $\left.{ }^{\Uparrow}\right)$. - c. S. brevignatha sp. n. $\left(\circlearrowright^{\lambda}\right) .-$ d. S. acutidens sp. n. $(\widehat{)})$. lechria. Eulechria increta Meyrick is one of these five species. In this study, it was found that Eulechria increta Meyrick is congeneric Stereodytis, due to the similarity of wing shape, wing pattern and the genitalia having a beaklike gnathos and thornlike cornutus. Hence, we transfer increta Meyrick to Stereodytis Meyrick.

\subsection{Stereodytis brevignatha Wang, sp. n.} (Figs. 1c, 2b)

Type material. Holotype $\widehat{\jmath}$, China: Kadoorie Agricultural Research Centre $\left(22.428^{\circ} \mathrm{N}\right.$, $\left.114.114^{\circ} \mathrm{E}\right)$, Tai Po, New Territories, Hong Kong Special Administrative Region, alt. $200 \mathrm{~m}$, 11.IV.2007, leg. Houhun Li et al.

Diagnosis. This new species can be distinguished from other congeners by the forewing with tornal stigma elongate and weakly joined with discocellular stigma; the valva in male nearly parallel-sided except cucullus, and the cucullus narrowed to a short process directing downward.

Description. Adult (Fig. 1c): Wing expanse $20.0 \mathrm{~mm}$. Head ochreous yellow. Antenna with scape ochreous yellow mixed with dark brown on dorsal surface, white on ventral surface; flagellum dark brown. Labial palpus black, tinged with ochreous at apex of second segment and on third segment; third segment shorter than second, acute. Thorax and tegula dark brown except greyish brown posteriorly. Forewing elongate, narrow; costal margin gently arched, apex somewhat rounded; termen oblique; ground color pale ochreous yellow, covered with greyish black scales; discal and discocellular stigmata greyish black, small and rounded; plical stigma large, diffused; tornal stigma elongate, weakly joined with discocellular stigma; greyish black fascia from distal portion of costal margin along termen to tornus, with obscure greyish yellow dots; fringe greyish brown except ochreous yellow along base. Hindwing greyish brown; fringe grey mottled brown, pale ochreous yellow along base. Fore and mid legs black; hind leg pale greyish brown, tinged with ochreous at base of tibia, ochreous yellow at apices of tarsal segments.

Male genitalia (Fig. 2b): Uncus broad at base, gradually narrowed toward apex, with pair of small pointed apical processes. Gnathos stout, broad at base, pointed and slightly bent down distally; dorsal margin arched, with dense teeth along basal $3 / 5$; ventral margin gentle, only slightly concave near apex. Valva broad, nearly parallel-sided except cucullus; cucullus more or less triangular, narrowed toward apex, directing downward, arched dorsally, deeply concave ven- 
Fig. 2. Genitalia of Stereodytis spp. - a. S. increta (Meyrick) (ठ). - b. S. brevignatha sp. n. $(ठ)$. - c. S. acuti-

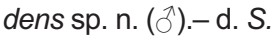
acutidens sp. n. (우).
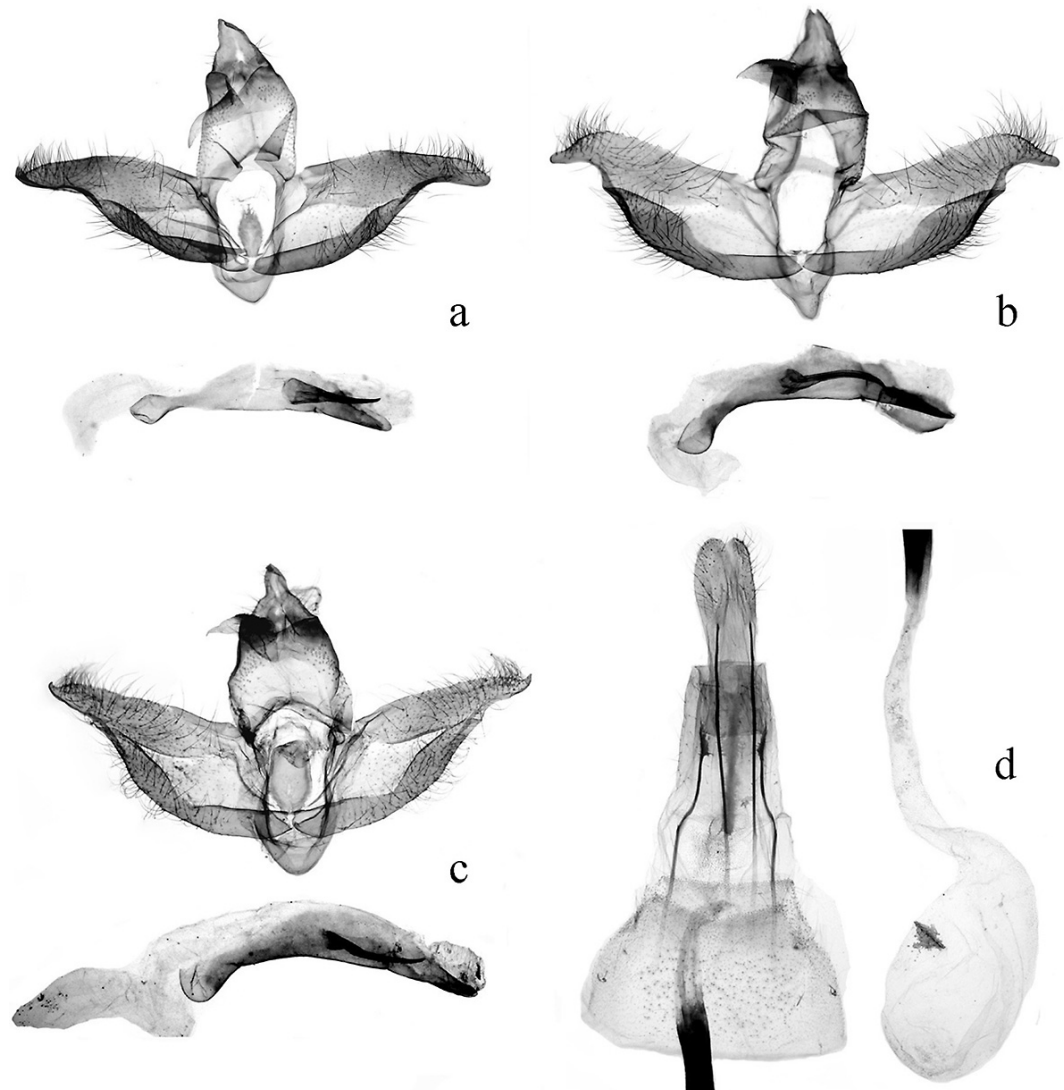

trally; transtilla weakly sclerotized. Sacculus sclerotized, its basal half narrow, distal half expanded near apex. Saccus small, rounded anteriorly. Juxta broad oval. Aedeagus about same length of valva, distinctly tapered distally; cornutus being a large thorn, broadened basally, pointed and curved distally.

Female: Unknown.

Distribution. China (Hong Kong).

Etymology. This specific name is from the Latin prefix brevi-, meaning short, and the etyma -gnathus, meaning gnathos, referring the stout gnathos.

\subsection{Stereodytis acutidens Wang, sp. n.} (Figs. 1d, 2c, 2d)

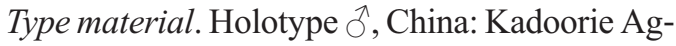
ricultural Research Centre $\left(22.428^{\circ} \mathrm{N}\right.$, $\left.114.114^{\circ} \mathrm{E}\right)$, Tai Po, New Territories, Hong Kong Special Administrative Region, alt. $200 \mathrm{~m}$,
20.IV.2007, leg. Houhun Li et al. Paratypes: 1 ○े, 1 , , same data as for holotype except dated 18 . and 21.IV.2007; 1 $\widehat{\jmath}$, Tai Mong Tsai, Sai Kung $\left(22.406^{\circ} \mathrm{N}, 114.305^{\circ} \mathrm{E}\right)$, Hong Kong Special Administrative Region, alt. 140 m, 15.IV.2007, leg. Houhun Li et al.

Diagnosis. This species can be separated easily from other members of the genus by the gnathos sinuate and spine-formed distally, the valva somewhat triangular, the cucullus hooked inward apically, and the juxta large elongate oval in the male genitalia.

Description. Adult (Fig. 1d): Wing expanse $16.0-18.0 \mathrm{~mm}$. Head ochreous yellow in male, whitish yellow in female. Antenna with scape ochreous yellow mixed with brown on dorsal surface, pale whitish yellow on ventral surface; flagellum dark brown on basal several segments, yellowish brown on the remainders. Labial palpus ochreous yellow, tinged with dark brown scales that become denser in basal $3 / 5$ on outer surface of second segment; third segment shorter 
than second, acute. Thorax and tegula dark brown on anterior half, greyish brown on posterior half. Forewing with costal margin gently arched, termen obliquely rounded; ground color pale grey, covered with dark brown scales; dark brown scales denser at base, along costal margin and termen; discal, plical and discocellular stigmata black, small and rounded; tornal stigma obscure; fringe greyish brown, tinged with ochreous yellow at base. Hindwing greyish brown; fringe grey mottled brown, greyish yellow basally. Fore leg black; mid leg ochreous yellow, dark brown on outer surface of tibiae of tarsi except ochreous yellow at apices; hind leg greyish ochreous, with scattered brown scales.

Male genitalia (Fig. 2c): Uncus broad at base, narrowed slightly to shrunk at $3 / 5$, distal $2 / 5$ narrow. Gnathos broad at base, narrowed to pointed apex, sinuate, spine-formed distally, with dense teeth along dorsal half, with dense granules in distal portion ventrally. Valva more or less triangular, broad at base; cucullus somewhat triangular, narrowed to pointed apex, hooked inward distally; costa nearly straight; transtilla strongly arched. Sacculus sclerotized, curved near middle. Saccus short, triangular. Juxta large, elongate oval. Aedeagus with distal 1/4 tapering, pointed apically; cornutus about $1 / 3$ length of entire aedeagus.

Female genitalia (Fig. 2d): Papillae anales short, rounded on caudal margin. Apophyses anteriores with sclerotized plate around base, curved near middle. Genital segment with a sclerotized, band-formed plate longitudinally. Ductus bursae long and slender, membranous except for sclerotized from about basal $1 / 3$ to middle. Corpus bursae oval, about 1/4 length of ductus bursae; signum quadrangular, with sclerotized transverse carina medially.

Distribution. China (Hong Kong). In addition to the type localities given, this species is also recorded from Kadoorie Farm \& Botanic Garden (Butterfly Garden, alt. $340 \mathrm{~m}$ ), two feng shui wood sites in Lam Tsuen Valley (alt. $60 \mathrm{~m}$ and 70 m) and coastal secondary shrubland at Lung $\mathrm{Ha}$ Wan, Clear Water Bay Country Park (alt. 25 m), all within Hong Kong's New Territories.

Biology. Imagoes have been recorded from February through April, in June and from August through October.

Etymology. This specific name is from the Latin acutidens, meaning acute dens, referring to the apically dentiform cucullus.

Acknowledgments. We wish to give our cordial thanks to Dr. Xinpu Wang and Haili Yu for their arduous work in collecting specimens, to Prof. Houhun Li for his kind suggestions on the manuscript. We are also grateful to Kadoorie Farm \& Botanic Garden for permission to access their collection and for supporting continuing fieldwork undertaken at KFBG by R. C. Kendrick. This study was supported by the National Natural Science Foundation of China (No. 30570206 and No. J0630963).

\section{References}

Clarke, J. F. G. 1963: Oecophoridae. Catalogue of the type specimens of Microlepidoptera in the British Museum (Natural History) described by Edward Meyrick. Trustees of the British Museum (Natural History), London, England, United Kingdom, 4: 83-472.

Common, I. F. B. 1997: Oecophorine genera of Australia. II. The Chezala, Philobota and Eulechria groups (Lepidoptera: Oecophoridae), Monographs on Australian Lepidoptera. - CSIRO Publishing, Australia, 5: 1-407.

Li, H.H. \& Zheng, Z. M. 1996: Methods and techniques of specimens of microlepidoptera. - Journal of Shannxi Normal University (Natural Science Edition), 24(3): 63-70.

Meyrick, E. 1914: Exotic Microlepidoptera, 1: 225-256. Meyrick, E. 1931: Exotic Microlepidoptera, 4: 161-192. 